\title{
Perancangan Sistem Informasi Rawat Jalan Pasien Di BP \& RB XYZ Dengan Metodologi Berorientasi Objek
}

\author{
Ahmaddul Hadi \\ Program Studi Pendidikan Teknik Informatika, Fakultas Teknik \\ Universitas Negeri Padang \\ Jl. Raya Bandung Sumedang Km. 21, Sumedang, Jawa Barat 45363 \\ dagadul@gmail.com
}

\begin{abstract}
The development of information technology very quickly and proved instrumental in a variety of activities, thus supporting the performance improvement of efficiency, effectiveness and productivity for various agencies, both agencies embodiment developed and prosperous society. Health sector is one of the important sectors of the government is one sector with huge potential for development can be integrated with the presence of information technology. BP \& RB Hospital XYZ which became one health care center in . BP \& RB Hospital XYZ is one health authority that is being developed. With a considerable number of patients, lead to problems in getting information about their patients, number of patients, number of visits, total revenues, drug inventory data and drug data that has been used by the hospital. Besides the issue of data collection and archiving of patient medical records is an important thing to note. By looking at existing problems, the BP \& RB Hospital XYZ , with the rapid development of information technology and by utilizing information technology, it is necessary to create an application that can overcome the problems encountered so as to improve health services in order to realize the vision of the society and mission Hospital BP \& RB XYZ .
\end{abstract}

Keywords- Information System, Computerized, Business Process.

\section{Pendahuluan}

Perkembangan ilmu pengetahuan dan teknologi memicu banyak kalangan untuk mencari alternatif pemecahan masalah di bidang teknologi sistem informasi. Penggunaan komputer sebagai alat bantu menyelesaikan pekerjaan di

bidang teknologi sistem informasi makin marak dan berkembang di segala bidang. Komputer dirasa memiliki banyak keunggulan, alasannya komputer dapat diprogram sehingga dapat disesuaikan dengan keinginan pemakainya.

Bahasa pemprogaman yang semakin banyak untuk memilih bahasa saat ini memberikan pilihan bagi programmer untuk memilih bahasa pemprogaman mana yang tepat untuk membangun sebuah aplikasi. Kesehatan adalah pelayanan publik yang bersifat mutlak dan erat kaitannya dengan kesejahteraan masyarakat. Untuk semua pelayanan yang bersifat mutlak, negara dan aparaturnya berkewajiban untuk menyediakan layanan yang bermutu dan mudah didapatkan setiap saat. Salah satu wujud nyata penyediaan layanan publik di bidang kesehatan adalah layanan Rumah Sakit BP \& RB XYZ. Tujuan umum dari adanya Rumah Sakit BP \& RB Medika Stannia adalah menyediakan layanan kesehatan yang bermutu namun dengan biaya yang relatif terjangkau untuk masyarakat setempat. Rumah Sakit BP \& RB Stannia adalah salah satu rumah sakit Swasta. Di dalam Rumah Sakit BP \& RB XYZ terdapat dua proses pembayaran yaitu : Bagian Timah membayar dengan cara bagian rawat jalan menagih kepada bagian Timah dengan berbentuk Nota Tagihan, sedangkan bagian Umum membayar dengan cara membayar ke bagian kasir yang telah tersedia. di Rumah Sakit BP \& RB XYZ ini terdapat beberapa bagian antara lain Poli Umum yaitu rawat jalan dan rawat inap yang meliputi : Administrasi, Kasir, Apotik UGD, Lab dan Gudang Obat.

Berdasarkan Observasi yang dilakukan di Rumah Sakit BP \& RB Medika Stannia bahwa Rumah Sakit BP \& RB Medika Stannia ini tiap hari melayani puluhan pasien yang datang. Saat ini sistem pengolahan data pasien tiap bagiannya masih dikerjakan dengan cara manual. Maka munculnya berbagai permasalahan dalam pengolahan data pasiennya. Masalah-masalah ini diantaranya adalah tingginya tingkat kesalahan dalam pengolahan data pasien (data pendaftaran, data pemeriksaan, data rujukan dan data laboratorium) dan lambatnya proses pencarian data pasien.

Berdasarkan Latar Belakang diatas, Maka sistem pengolahan data pasien yang ada di Rumah Sakit BP \& RB Medika Stannia ini harus diperbaharui agar masalahmasalah yang muncul dalam pengolahan data pasien ini bisa cepat teratasi.

\section{LANDASAN TEORI}

\section{A. Sistem Informasi}

Pada dasarnya system ini merupakan sesuatu yang memiliki bagian atau komponen yang salinh berinteraksi 
untuk mencapai tujuan tertentu dengan melalui tiga tahapan, yaitu: input, prosess dan output.

Sistem dapat didefinisikan dengan pendekatan prosedur dan dengan pendekatan komponen [1]. Dengan pendekatan prosedur, sistem dapat didefinisikan sebagai kumpulan dari prosedur-prosedur yang mempunyai tujuan tertentu, contoh dari sistem ini adalah sistem akuntasi. Pada sistem dapat didefinisikan sebagai kumpulan dari prosedur- prosedur penerimaan kas, pengeluaran kas, penjualan, pembelian dan buku besar. Sedangkan dengan pendekatan komponen, sistem yang dapat didefinisikan sebagai kumpulan dari komponen yang saling berhubungan satu dengan yang lainnya membentuk satu kesatuan untuk mencapai tujuan tertentu, contohnya adalah sistem computer. Pada sistem ini dapat didefinisikan sebagai kumpulan dari perangkat lunak dan perangkat keras [1].

Jadi dari pendefinisian diatas dapat diambil suatu kesatuan atau kumpulan yang terdiri dari dua atau lebih komponen yang saling berinteraksi untuk mencapai tujuan.

Suatu hal akan layak dikatakan sebuah sistem jika telah memenuhi delapan karakteristik sistem, yaitu sebagai berikut :

- Suatu sistem mempunyai komponen-komponen sistem (components) atau subsistem-subsistem.

- Suatu sistem mempunyai batas sistem (boundary).

- Suatu sistem mempunyai lingkungan luar sistem (environment).

- $\quad$ Suatu sistem mempunyai penghubung (interface).

- Suatu sistem mempunyai masukan (input).

- Suatu sistem mempunyai pengolahan (process).

- Suatu sistem mempunyuai keluaran (output).

Suatu sistem mempunyai tujuan (goal) tau sasaran (objective).

\section{B. Analisa dan Perancangan Sistem Berorientasi Obyek}

Analisa sistem dapat dinyatakan sebagai pemisahan suatu hal dengan bagian - bagian tertentu. Bagian - bagian tersebut kemudian dipelajari dan dievakuasi untuk mengetahui apakah terdapat cara - cara yang lebih baik untuk memenuhi kebutuhan manajemen. Analisa sistem adalah proses menentukan kebutuhan sistem apa yang harus dilakukan sistem untuk memenuhi kebutuhan klien, bukanlah bagaimana sistem tersebut diimplementasikan [2]. Konsep dasar berorientasi objek mencapai kematangannya pada saat masalah analisis dan desain menjadi lebih diperhatikan dari pada masalah coding. Secara fisik, pengertian berorientasi objek berarti bahwa kita mengorganisasi perangkat lunak sebagai kumpulan dari objek tertentu yang memiliki struktur data dan perilakunya [2].

\section{Basis Data}

Konsep dasar berorientasi objek mencapai kematangan pada saat masalah analisis dan desain menjadi lebih diperhatikan dari pada masalah coding. Secara spesifik, pengertian "berorientasi objek" berarti bahwa "kita mengoraganisasi perangkat lunak sebagai kumpulan dari objek tertentu yang memiliki struktur data dan perilakunya"
[2]. Terdapat beberapa cara untuk menentukan karakteristik dalam pendekatak berorientasi objek, tetapi secara umum mencakup empat hal, yaitu identifikasi, klasifikasi, polymorphism (polimorfisme) dan inheritance (pewarisan).

Metodologi pengembanagn sistem berorientasu objek mempunyai tiga karakteristik utama, yaitu :

1) Encapsulation

Encapsulation (pengkapsulan) merupakan dasar untuk pembahasan ruang lingkup program terhadap data yang diproses.

\section{2) Inheritance}

Inheritance (Pewarisan) adalah tehnik yang menyatakan bahwa anak dari objek akan mewarisi data / atribut dan metode dari induknya langsung. Sifat yang dimiliki oleh kelas induknya tidak perlu diulang dalam setiap subkelasnya.

\section{3) Polymorphism}

Polymorphism (polimorfisme) yaitu konsep yang menyatakan bahwa sesuatu yang sama dapat mempunyai bentuk dan perilaku berbeda.

\section{Entity Relationship Diagram (ERD)}

Selama analisis, perhatian kita adalah pada yang harus dikerjakan sistem, selama perencanaan keputusan dibuat tentang bagaimana pemecahan masalah akan dikerjakan. Perancangan sistem berorientasi objek merupakan proses spesifikasi yang terperinci atau pendefenisian dari kebutuhan - kebutuhan fungsional dan persiapan untuk rancang bangun implementasi yang menggambarkan bagaimana suatu sistem dibentuk, untuk mengembangkan suatu sistem baru dilakukan dengan menguraikan hubungan proses - proses dalam bentuk diagram - diagram.

Object - Oriented Design merupakan tahap lanjutan setelah Analisis Berorientasi Objek dimana tujuan sistem diorganisasikan ke dalan subsistem berdasar struktur dan arsitektur yang dibutuhkan [2].

Tahap -tahap yang dilakukan dalam perancangan berorientasi objek sebagai berikut :

1) Perancangan Basis Data

Merupakan tahap merancang basis data yang diterapkan oleh sistem.

\section{2) Diagram Interaksi (Interaction Diagram)}

Interaction Diagram menggambarkan interaksi antar objek (instan dari kelas) didalam dan sekitar sistem yang menekankan pada pesan (message) apa yang disampaikan dan digambarkan dengan menekankan dimensi waktu atau oeran masing-masingnya.

\section{3) Diagram Kelas (Class Diagram)}

Class adalah sebuah spesifikasi yang akan dihasilkan sebuah objek dan merupakan inti dari penegmbanagn dan desain berorientasi objek.

\section{4) Diagram Komponen (Component Diagram) \\ Component diagram menggambarkan struktur dan} hubungan antar komponen piranti lunak termasuk ketergantungan (dependency) diantaranya. 
5) Diagram Arsitektur Sistem (Deployment Sistem)

Deployment diagram menggambarkan arsitektur sistem dan bagaimana komponene di-deploy dalam infrastruktur sistem.

6) Normalisasi

Proses pengelompokkan atribut dari relasi sehingga membentuk Well Structure Relation, normalisasi merupakan sebuah teknik dalam logical design sebuah database.

\section{E. Teori Proyek}

1) Stakeholder

Stakeholder merupakan

manusia, komunitas

individu, sekelompok keseluruhan maupun secara parsial yang memiliki hubungan serta kepentingan terhadap perusahaan. Individu, kelompok, maupun komunitas dan masyarakat dapat dikatakan sebagai stakeholder jika memiliki karakteristik yaitu mempunyai kekuasaan, legitimasi, dan kepentingan terhadap perusahaan.

\section{2) Work Breakdown Structure (WBS)}

WBS adalah metode pengorganisasian proyek menjadi struktur pelaporan hierarkis. WBS digunakan untuk melakukan Breakdown atau memecahkan tiap proses pekerjaan menjadi lebih detail. Hal ini dimaksudkan agar proses perencanaan proyek memiliki tingkat yang lebih baik. WBS disusun berdasarkan dasar pembelajaran seluruh dokumen proyek yang meliputi kontrak, gambargambar, dan spesifikasi. Proyek kemudian diuraikan menjadi bagian-bagian dengan mengikuti pola struktur dan hirarki tertentu menjadi item-item pekerjaan yang cukup terperinci, yang disebut sebagai Work Breakdown Structure.

\section{3) Milestone}

Milestone adalah suatu bagian item pekerjaan yang dibuat seolah-olah menjadi temporary finish atau selesai sementara atas sekelompok atau serangkaian pekerjaanpekerjaan yang menjadi bagian dari schedule besar. Item pekerjaan yang dijadikan milestone harulah item pekerjaan yang dianggap menjadi bagian penting sebelum melanjutkan pekerjaan berikutnya atau berpengaruh atas kelangsungan pekerjaan berikutnya.

\section{F. Pengertian Rencana Anggaran Biaya (RAB)}

RAB (Rencana Anggaran Biaya) adalah penghitungan banyaknya biaya yang diperlukan untuk bahan dan upah, serta biaya-biaya lain yang berhubungan dengan pelaksanaan bangunan atau proyek, baik secara kasar/taksiran maupun secara teliti. Dalam penghitungan RAB suatu proyek, sering kali membutuhkan sebuah aplikasi program computer agar penghitungan RAB cepat dan akurat.

\section{G. Pengertian Manajemen Proyek}

Manajemen dapat diartikan sebagai ilmu dan seni tentang upaya memanfaatkan semua sumber daya yang dimiliki untuk mencapai tujuan secara efektif dan efisien.

Sebuah proyek adalah sebuah pekerjaan berbatas waktu yang menghasilkan produk tertentu yang unik, layanan, atau bentuk hasil lainnya. Sedangkan manajemen proyek adalah aplikasi dari sebuah pengetahuan, keahlian, alat bantu dan teknik tertentu untuk menyelaraskan kegiatan-kegiatan proyek agar berjalan sesuai dengan kebutuhan proyek utama.

Mengelola proyek terdiri dari : mengidentifikasikan kebutuhan, menentukan tujuan yang jelas, menyeimbangkan antara kualitas, cakupan, waktu, dan biaya proyek,serta mampu mengadaptasi berbagai spesifikasi, rencana, dan pendekatan-pendekatan berbeda dari berbagai pemangku kepentingan yang berbeda.

\section{H. Pengertian Responsibility Assignment Matrix (RAM)}

Responsibility assignment matrix (RAM) atau lebih dikenal dengan istilah RACI, adalah matriks yang menggambarkan peran berbagai pihak dalam penyelesaian suatu pekerjaan dalam suatu poyek atau proses bisnis. Matriks ini terutama bermanfaat dalam menjelaskan peran dan tanggung jawab antar bagian di dalam suatu proyek atau proses.

\section{Pengertian Deliverables}

Deliverables adalah sebuah output dari proyek yang dapat diukur seperti laporan, alpha tested produk, dan indicator-indicator kemajuan pengerjaan perangkat lunak.

\section{J. Pengertian Project Risk}

Peristiwa tidak pasti yang bila memiliki pengaruh positif atau negative terhadap minimal satu tujuan proyek (waktu, biaya, ruang lingkup, mutu). Resiko mungkin memiliki satu atau lebih penyebab, yang bila terjadi memiliki satu atau lebih dampak.

\section{K. Pengertian Project Execution Plan}

Sebuah rencana eksekusi suatu proyek sangat erat kaitannya dengan estimasi biaya, dimana keduanya saling bergantung dan tidak akan terpenuhi keduanya secara total jika satu diantara keduanya tidak terselesaikan.

\section{Project Execution Plan}

\section{A. PEP Project Execution Plan}

Pelaksanaan Rencana Proyek (PEP) adalah dokumen operasional untuk proyek yang direncanakan. Hal ini dimiliki, dipelihara dan dimanfaatkan oleh Manajer Proyek dan Tim Proyek untuk mendukung pengiriman output proyek yang teah disepakati. PEP adalah tanggung jawab Manajer Proyek dan merupakan aliran atau jalur dimana memungkinkan efektif sehari-hari (operasional) pengelolaan dan pengendalian proyek. PEP ini memperluas Rencana Bisnis Proyek yang merupakan rencana yang telah disetujui menggambarkan "apa" 
yang akan terjadi dalam proyek. Rincian PEP "bagaimana" Tim Proyek akan melaksanakan tugas / kegiatan mereka untuk memastikan bahwa "apa" akan terjadi. Dokumen ini menyediakan anggota Tim Proyek baru, atau Manajer Proyek baru dengan kemampuan untuk memulai selama proyek, dan terus melakukan kegiatankegiatan proyek secara konsisten dan berkesinambungan. Dokumen harus ditinjau ulang dan diubah untuk memenuhi kondisi berubah sesama masa hidup proyek.

\section{B. Identifikasi Deliverables}

Dalam manajemen proyek, hasil kerja (bahasa Inggris : deliverable) adalah objek berwujud dan atau berwujud yang merupakan hasil pelaksanaa objek yang diserahkan pada client, sebagai bagian dari suatu kewajiban atau obligasi. Istilah yang biasa dikaitkan decara spesifik dengan objektif ini, dapat berupa suatu kata benda, produk, atau artefak yang harus dibuat dan di berikan sebagai bagian kewajiban. Dalam hal ini deliverables di bagi menjadi 2 (dua) jenis yaitu tangible deliverables (asset fisik) dan intangible deliverables (asset non fisik).

\section{Penjadwalan Proyek}

Pengorganisasian kegiatan proyek adalah suatu pengembangan proyek harus diorganisasikan untuk menghasilkan output yang terukur bagi manajemen dan penentuan progress.

\section{Rencana Anggaran Biaya (RAB)}

Yang dimaksud dengan Rencana Anggaran Biaya (RAB) suatu bangunan atau proyek adalah perhitungan banyaknya biaya yang diperlukan untuk bahan dan upah, serta biaya-biaya lain yang berhubungan dengan pelaksanaan bangunan atau proyek tersebut. Anggaran Biaya merupakan harga dari bangunan yang dihitung dengan teliti, cermat dan memenuhi syarat. Anggaran biaya pada bangunan yang sama akan berbeda-beda antara daerah satu dengandaerah yang lain. Hal ini disebabkan karena perbedaan harga bahan dan upah tenaga kerja.

1) Biaya Personil

Tabel 1. Biaya Personil

\begin{tabular}{|l|l|l|l|l|}
\hline No. & $\begin{array}{l}\text { Personil } \\
\text { Tim Proyek }\end{array}$ & Volume & $\begin{array}{l}\text { Honor/Kegiat } \\
\text { an (RP) }\end{array}$ & $\begin{array}{l}\text { Jumlah } \\
\text { (RP) }\end{array}$ \\
\hline 1 & $\begin{array}{l}\text { Project } \\
\text { Manager }\end{array}$ & & & \\
\hline 2 & $\begin{array}{l}\text { Sistem } \\
\text { Analis }\end{array}$ & & & \\
\hline 3 & Programmer & & & \\
\hline 4 & Instruktur & & & \\
\hline 5 & Keuangan & & & 0 \\
\hline & Total & & & \\
\hline
\end{tabular}

2) Biaya ATK

Tabel 2. Biaya ATK

\begin{tabular}{|l|l|l|l|l|}
\hline No. & Uraian & Volume & $\begin{array}{l}\text { Harga } \\
\text { Satuan } \\
\text { (RP) }\end{array}$ & Jumlah (RP) \\
\hline 1 & $\begin{array}{l}\text { Kertas } \\
\text { HVS } \\
\text { gr }\end{array}$ & 30 rim & 20.000 & 60.000 \\
\hline 2 & $\begin{array}{l}\text { Kertas } \\
\text { Buram }\end{array}$ & 2 rim & 35.000 & 70.000 \\
\hline 3 & Printer & 1 set & 200.000 & 200.000 \\
\hline 4 & $\begin{array}{l}\text { Tinta } \\
\text { Hitam } \\
\text { Printer }\end{array}$ & 4 set & 25.000 & 100.000 \\
\hline 5 & $\begin{array}{l}\text { Tinta } \\
\text { Warna } \\
\text { Printer }\end{array}$ & 2 set & 40.000 & 80.000 \\
\hline & Total & & & \\
\hline
\end{tabular}

\section{E. Tabel RAM (Responsible Assignment Matrix)}

Responsibility Assignment

Matrix (RAM) merupakan suatu bentuk pemetaan sumber daya kepada aktifitas dalam tiap prosedur. Adapun Tabel RAM yang digunakan dalam skripsi ini adalah Diagram RACI.

\section{F. Skema Struktur Project}

Struktur organisasi proyek secara umum dapat diartikan dua orang atau lebih yang melaksanakan suatu ruang lingkup pekerjaan secara bersama-sama denga kemampuan dan keahliannya masing-masing unbtuk mencapai suatu tujuan sesuai yang direncanakan.

\section{G. Analisa Resiko}

Resiko proyek adalah peristiwa tidak pasti yang bila terjadi akan memiliki efek positif atau negative terhadap tujuan proyek (bisa berupa biaya, waktu, mutu, ruang lingkup). Resiko mungkin memiliki satu atau lebih penyebab, yang bila terjadi memiliki satu atau lebih dampak. Ada setidaknya 4 jenis resiko yang selama ini sudah dikenal orang, yakni :

1) Resiko Operasional yakni resiko yang berhubungan dengan operasional organisasi, antara lain misalnya resiko yang mencangkup sistem organisasi, proses kerja, teknologi dan sumber daya manusia.

2) Resiko Finansial yakni resiko yang berdampak pada kinerja keuanganorganisasi seperti kejadian resiko akibat dari fluktuasi mata uang, tingkat suku bunga termasuk resiko pemberian kredit, likuiditas kondisi pasar.

3) Hazard Risk yaitu resiko yang terkait dengan kecelakaan fisik seperti kerusakan karena kebakaran, gempa bumi, ancaman fisik dll. 
4) Resiko strategi yaitu resiko yang ada hubungannya dengan strategi perusahaan, politik, ekonomi, hukum. Resiko ini juga terkait dengan reputasi kepemimpinan organisasi dan perubahan selera pelanggan.

\section{H. Meeting Plan}

Meeting Plan merupakan rapat perencanaan proyek dengan tujuan untuk menyamakan presepsi diantara semua pihak.

\section{HASIL DAN PEMBAHASAN}

\section{A. Use Case Diagram}

Use case diagram yang diusulkan pada Sistem Informasi Rawat Jalan Rumah Sakit Medika Stannia adalah sebagai berikut :

1) Petugas Pendaftaran

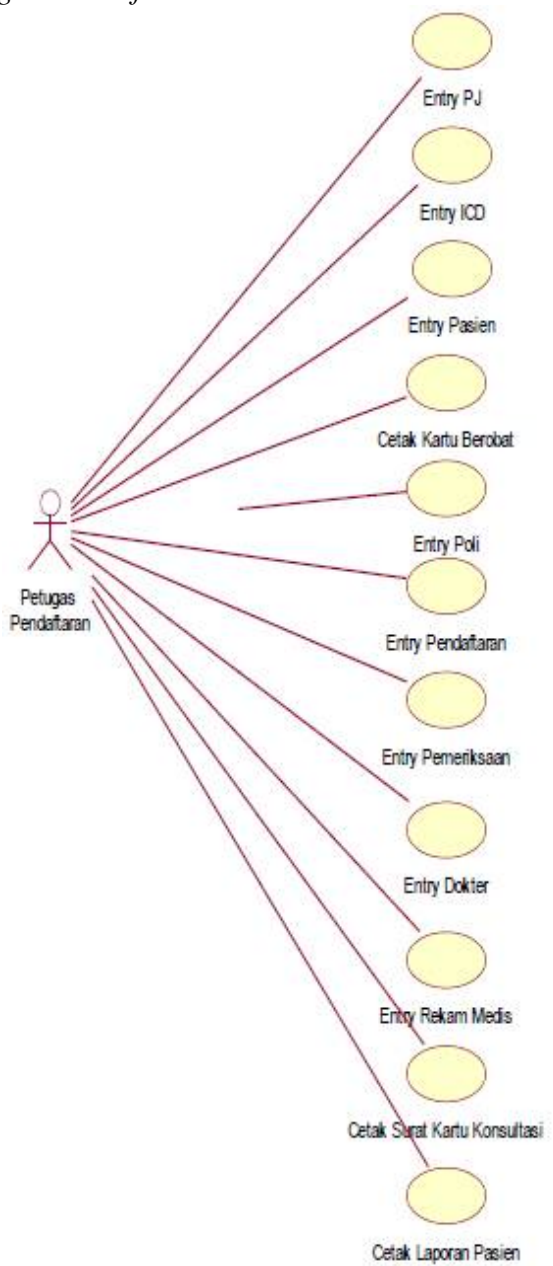

Gambar 1. Use Case Diagram Petugas Pendaftaran 2) Aktor Bagian Kamar Obat

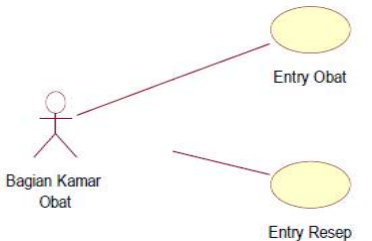

Gambar 2. Use Case Diagram Aktor Bagian Kamar Obat

\section{3) Aktor Bagian Kasir}

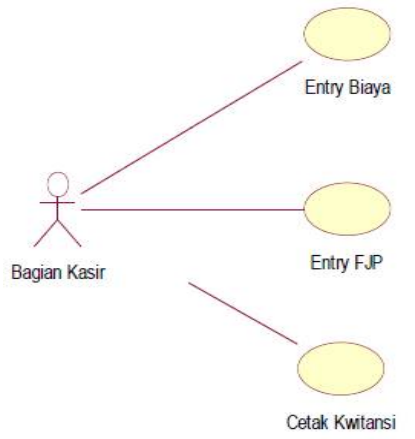

Gambar 3. Aktor Bagian Kasir

B. Entity Relationship Diagram (ERD)

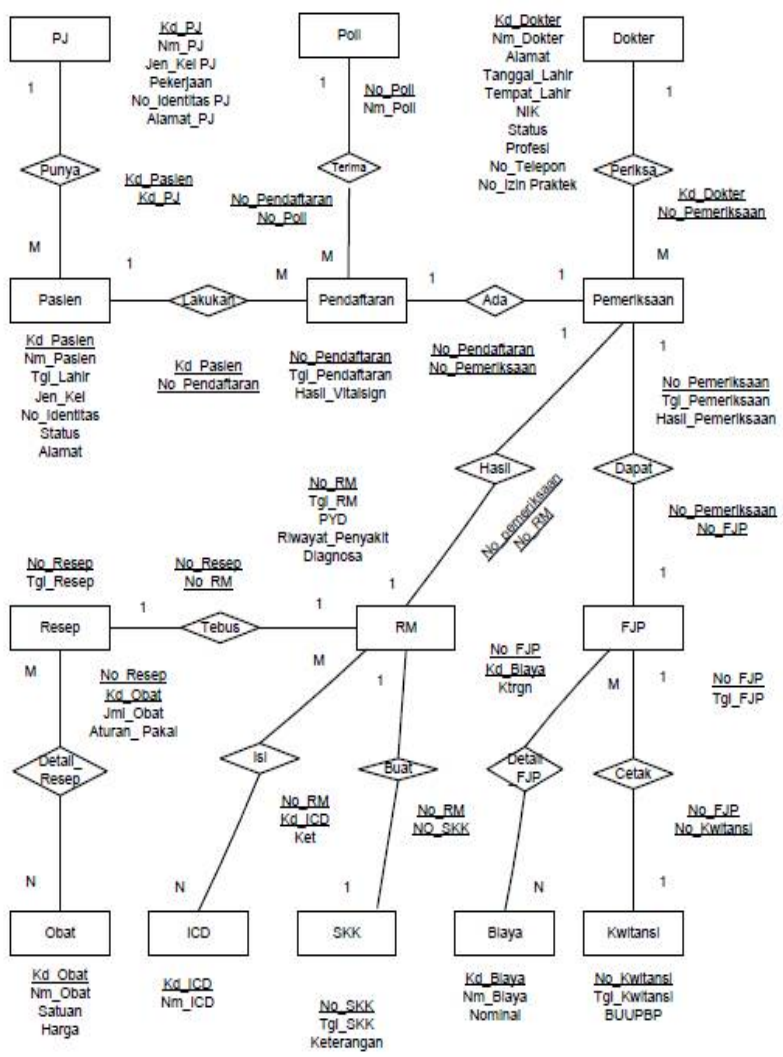

Gambar 4. ERD 
C. Struktur Tampilan

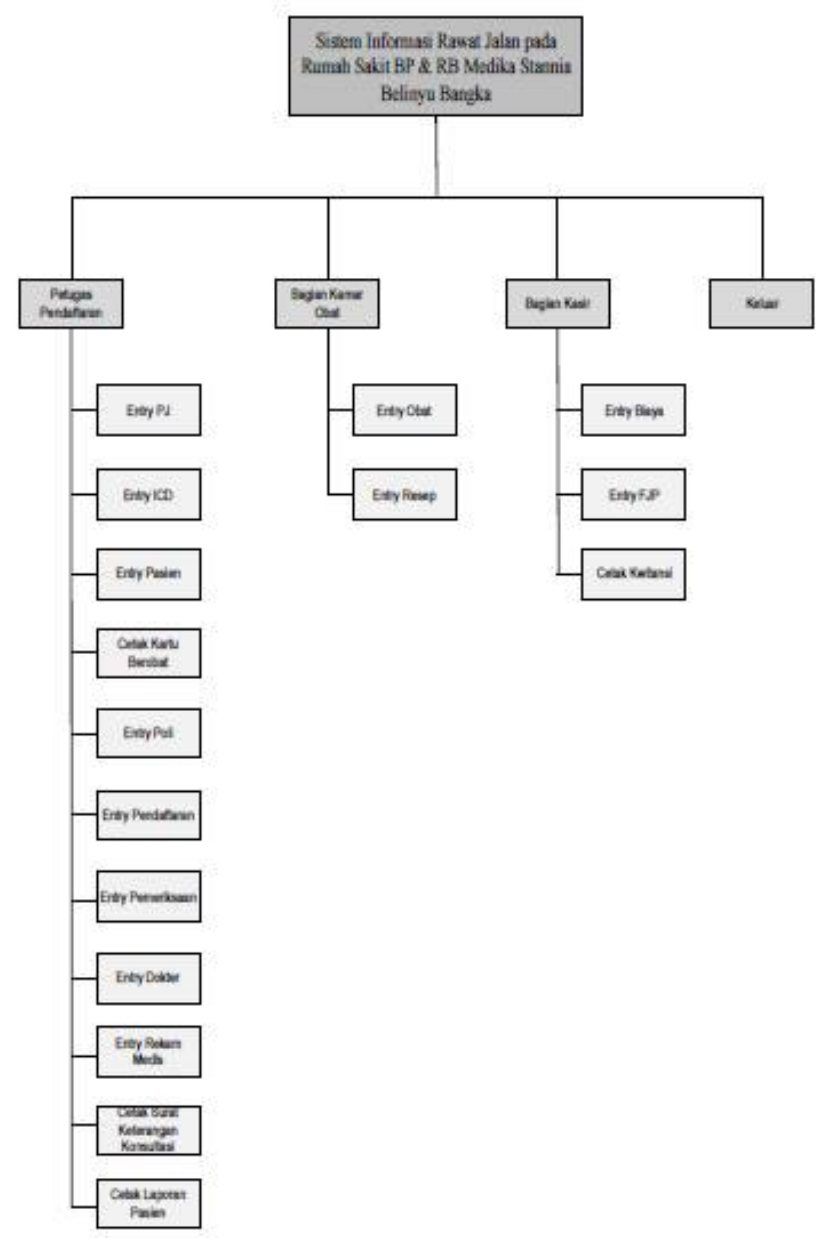

Gambar 5. Struktur Tampilan

D. Rancangan Layar

\section{1) Form Pendaftaran}

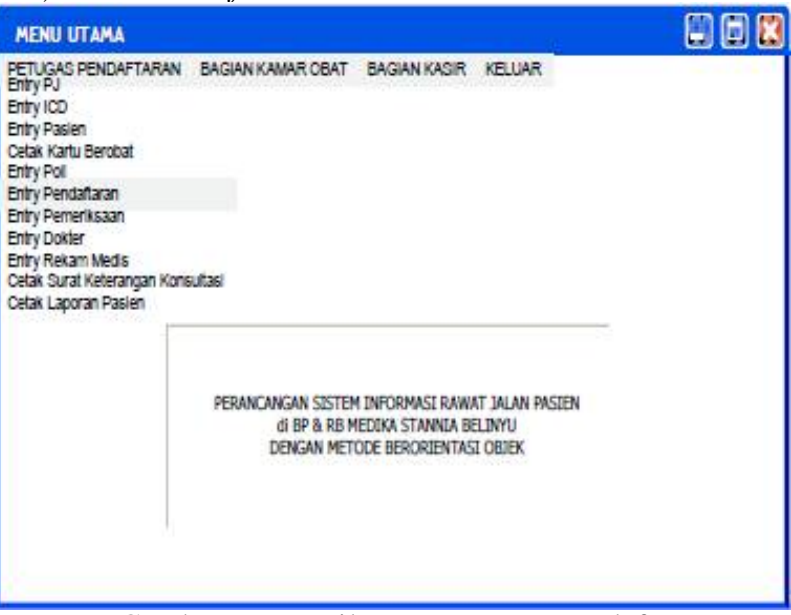

Gambar 6. Tampilan Layar Form Pendaftaran

\section{2) Entry Dokter}

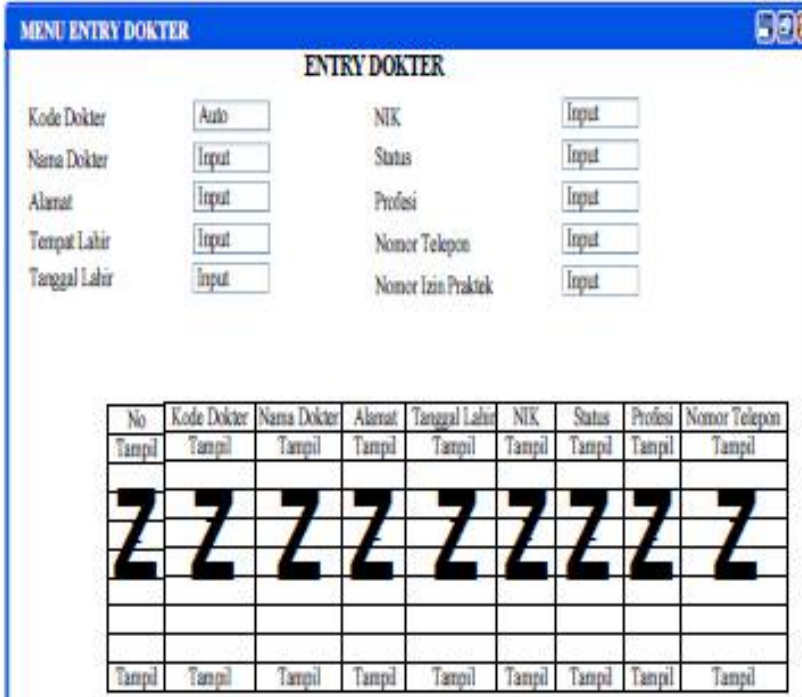

\section{Smpan Ubah Hapus Bota Kelvar}

Gambar 7. Tampilan Layar Entry Dokter

3) Cetak Kwitansi

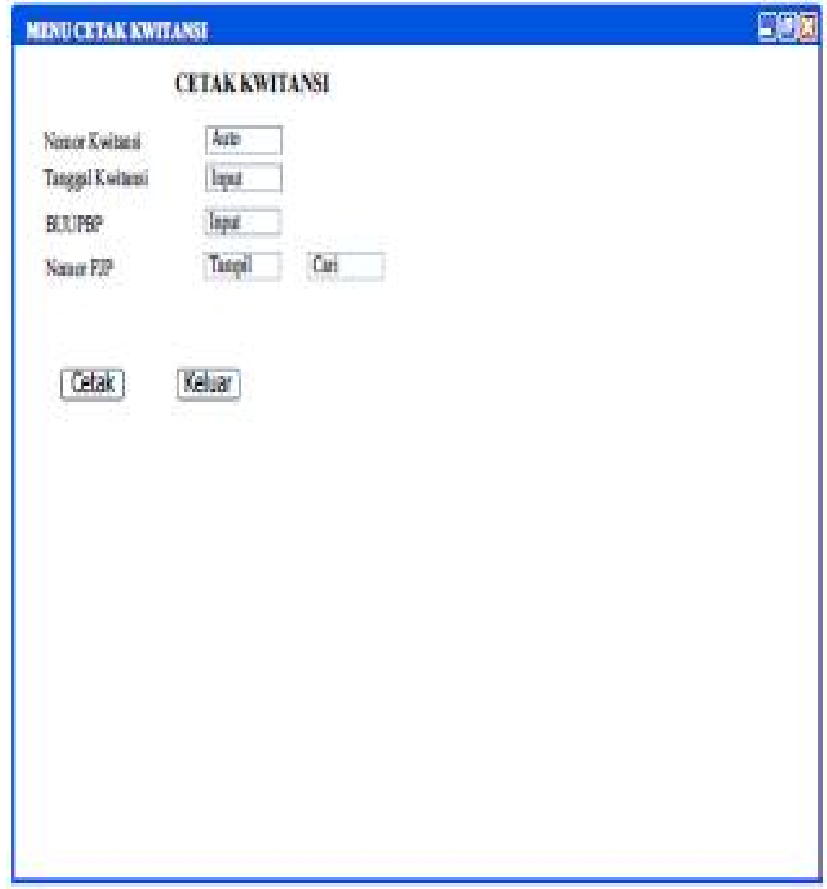

Gambar 8. Tampilan Layar Cetak Kwitansi 


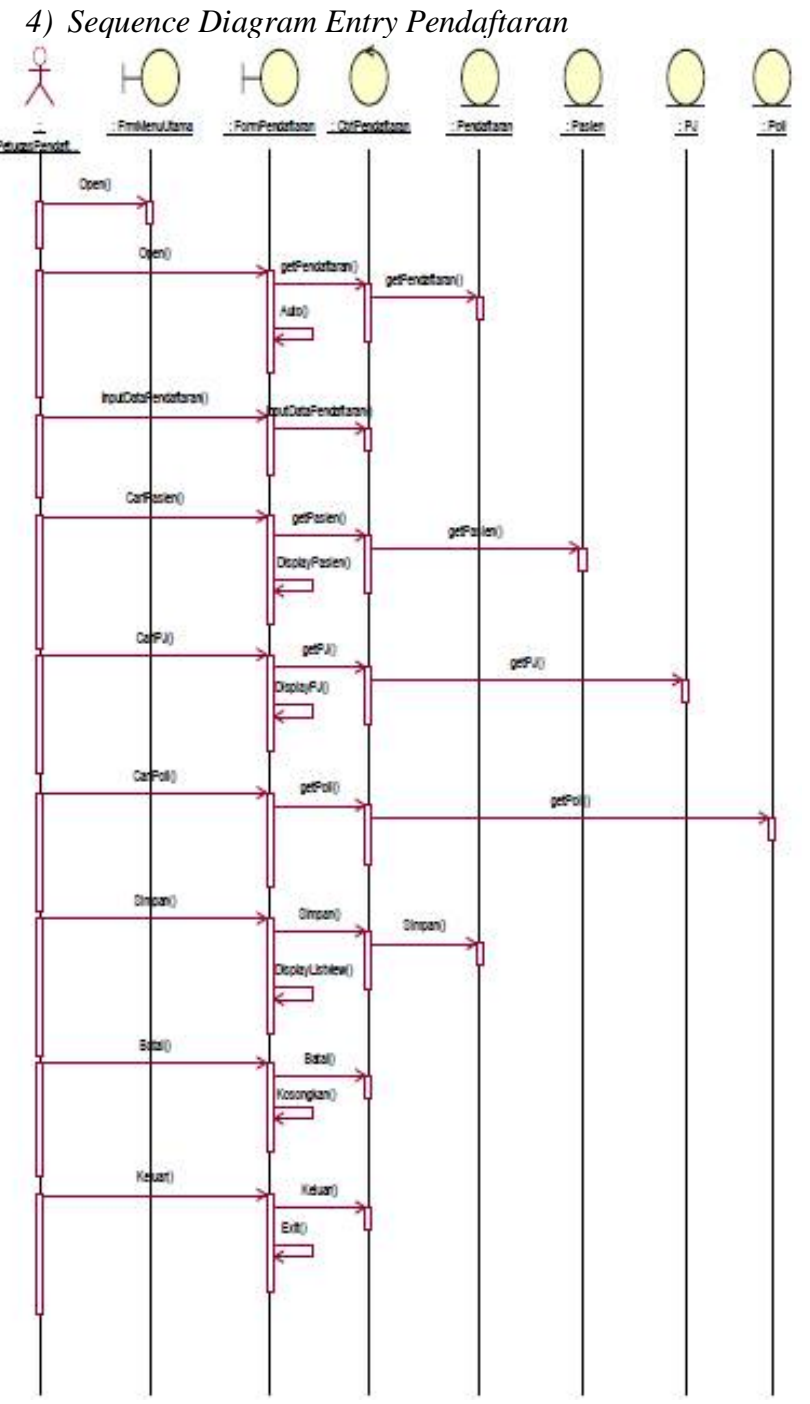

Gambar 9. Sequence Diagram Entry Pendaftaran

\section{5) Entry Data Peminjaman}

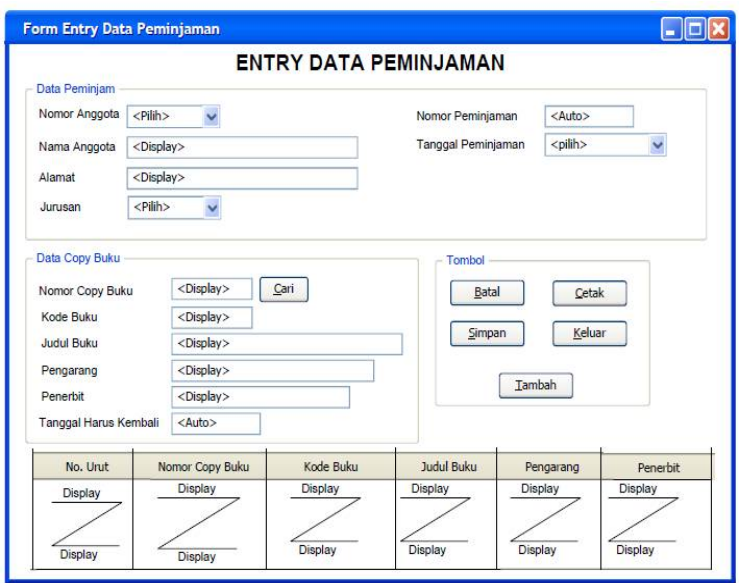

Gambar 10. Tampilan Layar Entry Data Peminjaman
6) Entry Data Pengembalian

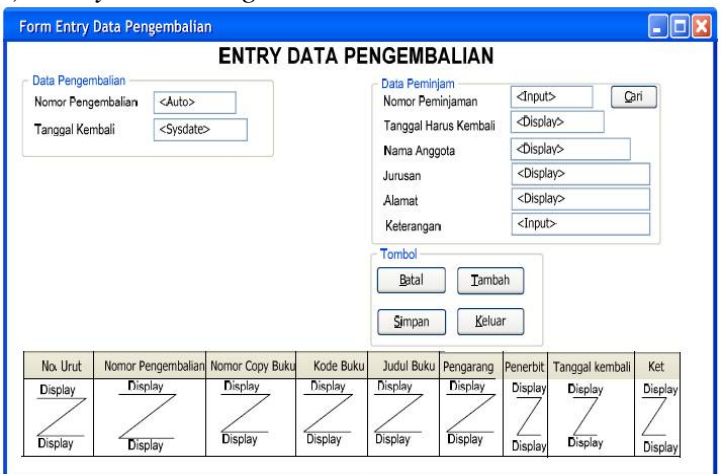

Gambar 11. Tampilan Layar Entry Data Pengembalian

7) Cetak Laporan Peminjaman

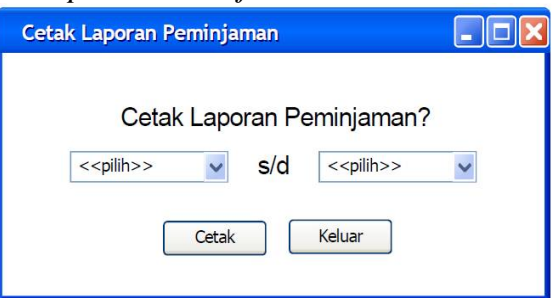

Gambar 12. Tampilan Layar Cetak Laporan Peminjaman

E. Rancangan Class Diagram (Entity Class)

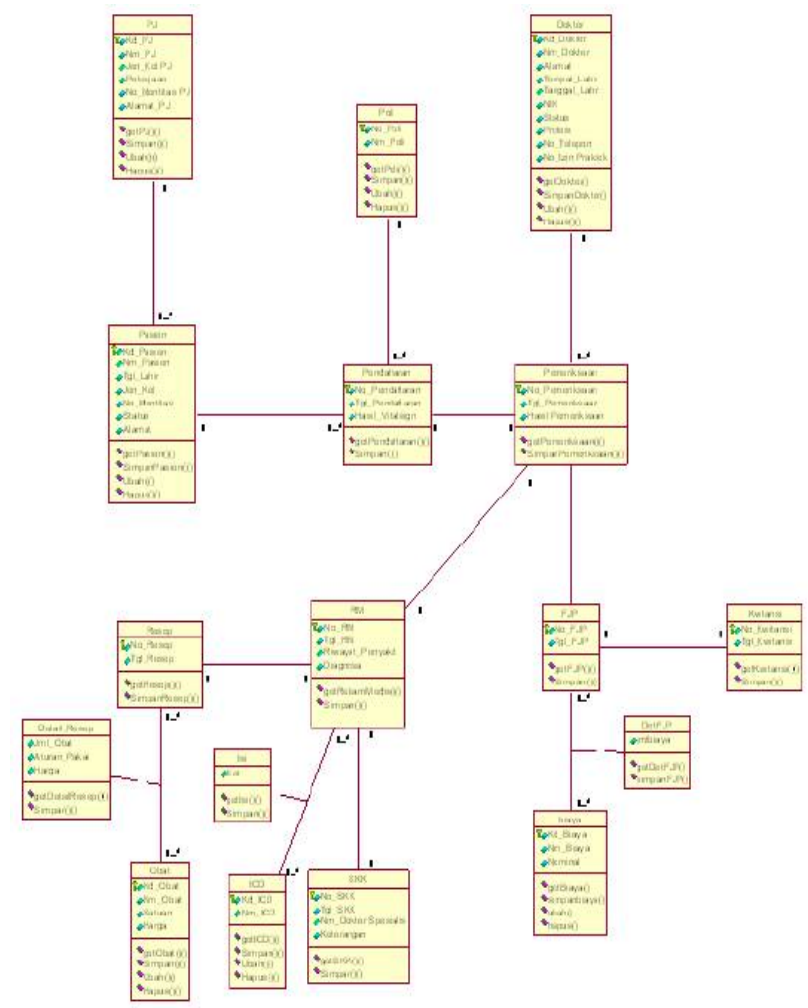

Gambar 13. Class Diagram 


\section{Penutup}

\section{A. Kesimpulan}

Dengan adanya penelitian dan perancangan sistem informasi pengolahan data pasien di Rumah Sakit BP \& RB , maka kesimpulan yang dapat penulis simpulkan yaitu :

- Penggunaan sistem lama banyak membutuhkan waktu untuk proses olah data. Maka dengan adanya sistem baru tersebut dapat membantu kinerja pegawai dengan mudah lebih menghemat waktu. Selain itu dapat mengurangi antrian pelayanan pasien yang lama.

- Dengan penggunaan sistem, maka informasi yang dihasilkan pun dapat diperoleh dengan mudah, dan tepat waktu. Karena pengoperasian olah laporan tersebut mudah.

- Dengan menggunakan sistem pencatatan yang sudah terkomputerisasi diharapkan masalah atau hambatan yang dihadapi dalam sistem manual dapat teratasi atau meminimalkan kesalahan yang terjadi dalam sistem manual seperti dalam penyajian informasi yang kurang cepat dan keakuratan data yang kurang terjamin.

\section{B. Saran}

- Saat ini sistem pengolahan data pasien di Rumah Sakit BP \& RB tiap bagiannya masih dikerjakan secara manual untuk itu diperlukan sistem yang baru, dengan dibangunnya sistem baru ini dharapkan dapat membantu dalam pengolahan data pasien yang lebih optimal, agar bisa melayani puluhan pasien tiap harinya.

- Untuk menjaga dari hal-hal yang tidak diinginkan seperti kehilangan data sebaiknya sistem baru ini dilakukan secara rutin dan hanya petugas Rumah sakit saja yang dapat mengakses sistem tersebut. Perlu melakukan back up data secara rutin seperti cadangan master data dan media penyimpanan harus terjamin seperti Flash disk, diskette atau hardisk

\section{DAFTAR PUSTAKA}

[1] Hartono Jogiyanto, (2005), Analisis \& Desain Sistem Informasi Pendekatan Terstruktur Teori dan Praktek Bisnis, Yogyakarta:Andi.

[2] AgungGregorius, (2003), Belajarsendiri: Pemrogrman PHP dengan Dreamweaver MX, Jakarta:Elex Media Koputindo.

[3] Connolly Thomas,(2002), Database systems : A Practical Approach to Design, Implemntation, and Management, Third Edition, England: Addition Wesley Publishing Company Inc.

[4] Jeffery, L. Whitten, et al. Metode Desain dan Analisis Sistem Edisi 1. Yogyakarta : Andi Madcoms, 2004. 